\title{
Markedness Theory in the Holy Bible with Reference to English, Syriac and Arabic Translations
}

\author{
Lubna M. Khoshaba
}

Asst. Lecturer, Lebanese French University / Erbil

\begin{abstract}
Markedness is a very comprehensive term which can be used in any discipline like phonology, morphology, syntax, semantics, pragmatics, social sciences, among many other disciplines. As for linguistics, it means the way words, phrases, are changed, added, deleted or foregrounded, mid-grounded and backgrounded. All these changes take place in an accordance with the intentionality of the speaker whenever a certain idea should be confirmed. This research paper studies the use of "markedness theory " in three translated versions of ten verses of the holy Bible ,namely (1) English,(2) Syriac and (3) Arabic. The main problem is that the study does not use the source language text since it is not available; therefore, a contrastive study will be conducted to see to what extent translators used the markedness theory in their renderings. This study hypothesizes that: (1) the confirmed messages or ideas are marked, and (2) the translators are aware of the marked elements. The main conclusions the study arrived at are: (1)the three versions: English, Syriac and Arabic were the output of communicative translations in that structurally speaking differences among the three versions are recognizable, and (2) confirmation of certain key-words which convey the gist of the verse has been marked and considered by the translators mainly by foregrounding and sometimes by midgrounding and backgrounding.
\end{abstract}

Keywords - markedness theory, foregrounding, middlegrounding, backgrounding, translation.

\section{INTRODUCTION}

Much ink was spilt on the "markeness theory" by phonologists, morphologists, syntacticians, semanticists, among many other scholars. However, to the best of our knowledge no study has been conducted about the use of "Markedness Theory" in the Holy Bible with reference to English, Syriac, and Arabic translations.T his paper is an attempt to abridge that gap. Markedness theory can be considered as one of the most important theories in structural linguistics, semantics, pragmatics, stylistics, among many other disciplines. Consequently, it received a great attention of scholars of all linguistic levels such as phonology, morphology, phraseology, syntax, semantics, pragmatics and stylistics and also all levels of literature such as poetry drama, novel, etc. This means that any study of markeness theory should be a multidisciplinary study tackling the notion of textuality, contextualityand intentionality. According to this theory, all languages of the whole globe, once they are used, they involve some elements or pieces of knowledge which are more basic and more important than other elements which are natural and normal. Those elements which are more important will be confirmed, i.e. will be marked according to their context by foregrounding, middlegrounding or backgrounding. Trubetzkoy and Jakobson (1931-1969: 306) who were representing Prague school propose the notion of markedness theory in terms of phonological contrast (see Yan-qin and FenyJuan ,2015:54).

Trubetzkoy and Jakobson (1969) believe that the notion of markedness posits that the term of polar oppositions at any level of language are not only opposites, but rather than they show an evaluative nonequivalence that is imposed on all oppositions. Generally, the unmarked form is the more frequent option and also the one that has the most neutral meaning. Greenberg (1966) was the first to study markedness in terms of distinctive features. Later on, Noyer (1992) and Harley and Ritter (2002) focus more narrowly on morphological markedness. Sauerland (2008) focuses; however, on semantic markedeness which is in fact one of Greenberg's test of markedness based on marked value.

In linguistics, markedness refers to the way words are changed or added in order to give a special meaning. The unmarked choice is just the normal meaning. For instance, the present tense is unmarked for English verbs, whereas the past tense is marked, e.g.

1. "travel"(unmarked).

2. "travelled" is morphologically marked by the suffix (-ed).

Likewise, the noun

3. "host" (unmarked). 
4. "hostess" is morphologically marked for femaleness by the suffix the (-ess).

In Arabic "مدير"(manger) is unmarked, whereas "مديرة"(a female manager) is marked.

Morphologically, Arabic nouns showing masculine and feminine is well-known for markedness, e.g.

"مدرس" (a male teacher)

"مدرسة" (a female teacher)

Leech (1969) states that in the case of contrast between two or more members of a category like "number", "case", "tense", one of them is called "marked". If it contains some extra "affix" as opposed to the unmarked member which does not.

Nordquist (2017:65) claims that in many areas of language, markedness is a state in which one linguistic element, (phoneme, morpheme, word, phrase) is more distinctively identified or (marked) than another.

The following examples on the level of the elements of the sentences are illustrative.

$$
\text { 1. }
$$

In fact, both the above mentioned sentences are correct whether syntactically or semantically; yet, the first one is the norm, whereas the second one is deviated from the norm by foregrounding the subject, and; therefore, it becomes "marked".

Let us have an example in English.

1. He went home yesterday. (Unmarked)

2. Yesterday, he went home. The sentence has been marked by foregrounding the adverb "yesterday".

The second sentence confirms the adverb "yesterday"; therefore, it has been foregrounded.

From what has been said, one can say that markeness is a case in which one element of language is made more prominent than the other elements either by foregrounding, middlegrounding, or backgrounding and this element may be a phoneme, morpheme phrase etc. This occurs in an accordance with the intention of the speaker or writer. Hence, comes the multiplicity study of this phenomenon which may be any level of linguistics, e.g. phonological, morphological, phraseological, syntactic, etc. or any level of literature, like poetry, play, novel, and any piece of literary style.

\section{FOREGROUNDING, MIDDLEGROUNDING AND BACKGROUNDING}

Foregrounding is a technique for making certain strange changes in Language, or it is a method of defamiliariasation in textual composition. Whether the foregrounded pattern deviates from a norm, or whether it replicates a pattern through parallelism the point of foregrounding as a stylistic strategy is that it should acquire salience in the act of drawing to itself (Nordquist, 2017:4).

In literature, foregrounding may be most readily identified with linguistic deviation. The violation of grammatical rules and conversations by which a poet transcends the normal communicative resources of the language, and awakens the reader, by freeing him from the grooves of cliché expressions, to a new perceptivity. Poetic metaphor, is a type of semantic deviation, is the most important instance of this type of foregrounding, e.g.

Before me stare a wolfish eye

Behind me creeps a groan or sigh (Davis 18711941)

The idea of foregrounding is that the clauses which make up a text can be divided into two clauses. These are clauses which in one way or another, elaborate the important ideas, adding specificity or contextual information to help in the interpretation of the central idea. The clauses which convey the most central or important information are called foregrounded clauses, and their propositional content is backgrounded information.(Cornish, 2014:10).

A great deal of stylistic foregrounding depends on an analogous process, by which some aspects of the underlying meaning is represented linguistically at more than one level: not only through the semantics of the textthe ideational and interpersonal meanings, as embodied and in the writer's choice of his role but also by direct relation in the lexicogrammar or phonology.

\subsection{Foregrounding Theory}

Foregrounding theory is a powerful theory that has started in the Greek philosophy, developed by the Russian and Czech theorists, and flourished in the $21^{\text {st }}$ century.

This theory is based on breaking up rules and norms by implementing devices of deviation and parallelism, yielding an aesthetic experience in the mind of the reader. The basic principles of the theory are: (1) defamiliarization in which foregrounding texts are striking and evocative, (2) affecting universal and related to specific type of individuals.

To sum up, foregrounding is striking, effective, time consuming and universal. It surprises the reader by violating the rules. Such violation triggers his feelings and requires much more time to understand and process the text, which in turn forces the reader to focus on the way the text is written more than the content. Finally, such effects are claimed to be universal irrespective of backgrounding or literary experience of the reader.
2.2 Myers-Scotton
(1993)
Model
of Markedness Theory 
Myers-Scotton (1993) Model provides a very useful framework within which to analyze different types of code switching, and the validity of the types of code switching. He believes that codeswitching is viewed as a positive linguistic phenomenon by the learners and the teachers and that it has specific functions in our multicultural and multilingual society.

This model is based on the patterns of language use and the functions fulfilled by code switching in different contexts and how these aspects affect the patterns of language use and functions of code switching in the class.

Myers-Scotton (1993:114) claims that the umarked code switching takes place when the addresser makes choice the unmarked index of the unmarked Rights and Obligations set in the speech exchange when he/she wishes to establish the Rights and Obligations set. According to Kieswetter (1995:16) the unmarked code carries the social meaning, rather than the individual switches. The unmarked code choice is used to indicate simultaneous identities (kieswetter, 1995:114), and usually consists of a continuous pattern of using two or more languages.

The Markedness Model consists of a set of general maxims which can be applied to any code choice. They are as follows:

1. The Unmarked Choice Maxim: Make your code choice the unmarked index of the unmarked rights and obligations set in talk exchanges when you want to affirm that rights and obligations set.

2. The Marked Choice Maxim: Make a marked choice which is not the unmarked index of the unmarked_rights and obligations set in an interaction when you wish to establish a new rights and obligations set as unmarked for the current exchange.

3. The Exploraty Choice Maxim: When an unmarked choice is not clear, use switching between speech varieties to make alternative explatory choices as (alternate) candidates for unmarked choice and thereby as an index of rights and obligations set which you favor.

4. Deference Maxim: Switch to a code which expresses deference to others when special respect is called for by the circumstances.

5. Virtuosity Maxim: Switch to whatever code is necessary in order to carry on the conversation/accommodate the participation of all speakers present.

\subsection{Marked Model as a Rational Actor Model:}

Rational Actor model, including the Markedness model, offer a great advantage over other current models of linguistic choice. From the outset, "being rational" constrains choices in an important way: Every choice in a speaker's repertoire does not have an equal chance of occurring. Instead, the goal to enhance rewards and minimize costs limits choices in a way that neither situational factors nor structural organization can do. The operative word regarding choices is not "possible" but "feasible" or advantageous or unconscious cognitive calculations.

One can say that although Rational Actor models such as the Marked Model do not claim that the assumption of rationality accounts for the data. That is, not only do Rational Actor models provide an explanation of why every potential choice does not occur with the same frequency, but they also provide a principled means for interpreting the choices that occur. From what has been said so far, it is believed that markedness model is considered as a rational actor model. As such, the Marked Model is integrated into a more comprehensive view of how social behaviors arise.

\subsection{Markedness Theory and Our Model:}

In our literature review, we reviewed two models of markeness theory. The first by Myers-Scotton (19931998) which is based on code switching approach that involves (1) sociolinguistic aspects of codeswitching, and (2) grammatical aspects of code switching. In regard to the sociolinguistic aspects of code switching, there are two models: (1) the markedness model of Myers which takes social norms as its starting point in analysis, and (2) the conversational codeswitching approach of $\mathrm{Li}$ (1994) and Auer (1995) which is based on face to face interaction or conversation as its starting point in analysis. Consequently, the first analysis can be seen as a top-down approach and the second as a bottom-up approach.

With regard to syntactic aspect of codeswitching this study employes the Matrix Language Frame model (Myers-Scotton, (1993 and 2002) to know the grammatical constrains on English, Syriac and Arabic codeswitching. Our analysis will be in coincidence with this model.

As for Berrendonner's Model of markedness theory, it seems that he viewed markedness in terms of foregrounding, middlegrounding and backgrounding which are based on macro-syntactic structure and microsyntactic structure. Berrendonner (1990:28) states that, syntactically, a given clause or phrase may depend on governing unit (lexicon, group, phrase or clause). Hence, it represents a background unit in purely formal, syntactic in terms of textuality, but at the same time, in terms of discourse. This may constitute foregrounded information 
in relation to the situation evoked via what be analyzed as its governing unit in syntactic unit.

Our model will be an eclectic one, whenever, there is prominence or salience, it will be considered as marked, whether it is phonological, morphological, phraseological, syntactic or even sentential. In our study, any shift and violation of the grammatical rules will be regarded as markedness.

\section{TRANSLATION, DATA ANALYSIS AND FINDINGS}

In this section, the modified model of Markedness Theory will be applied to different verses derived from the Holy Bible. The analysis will cover renderings of these verses into Syriac and Arabic to see how markedness theory is realized in these three languages.

\subsection{The Concept of Translation}

Catford (1965) states that translation is an act of replacing linguistic units from a source language by a target language. He also defines as the translation is the replacement of textual material in one language (SL) by equivalent textual material in another language (TL).

Nida and Taber (1982) say that "translation consists in reproducing in the receptor language the closest natural equivalence of the source language message, first in terms of meaning and secondly in terms of style.

Newmark (1982, 1988) defines translation in terms of finding equivalence (e.g. word-for-word translation, literal translation, formal equivalence and semantic translation), and transference of meaning(e.g. communicative translation, dynamic equivalence, free translation and adaptation).

From the aforementioned definitions, we believe that there are two types of definitions. The first one in terms of finding equivalence like Catford (1965) and Nida \& Taber (1982). The second one is in terms of transference of meaning. Our definition will be in terms of transference of meaning in that the lexicons, syntactic structures, semantic and pragmatic elements as well as cultural norms will be replaced by their equivalents in the target language. Hence, comes the eclectic definition since all the elements whether linguistic or non-linguistic are included. Thus, the transference of meaning and intentionality can be achieved as much as possible.

\subsection{Newmark's (1988) Types of Translation}

The terms of communicative and semantic translation represent Newmark's main contribution to general translation theory. Al-Sulaimaan(2016) summarizes the basic features of communicative and semantic translations as follows:

\subsubsection{Semantic Translation}

1. It is authored-centred.
2. It pursues author's process related to thought.

3. It is faithful and more literal.

4. It is informative.

5. It is personal.

6. It stresses meaning.

7. The translator has no right to add, delete and change.

\subsubsection{Communicative Translation}

1. It is reader-centred.

2. It pursues author's intention related to speech.

3. It is faithful and freer.

4. It is effective.

5. It is social.

6. It stresses the force of the message.

7. The translators can delete, correct background whenever he believes that is important.

\subsection{Data Analysis}

A. English Version (1):Jesus said to them " Only in his hometown, among his relatives and in his own house is a prophet without honor." (Mark 6:4 p. 118)

B. English Marked Version: Only in his hometown, among his relatives and in his own house is a prophet without honor.

C. English Norm Version: A prophet is without honor only in his hometown, among his relatives and in his own house.

Syriac Version:

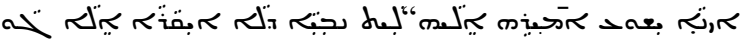

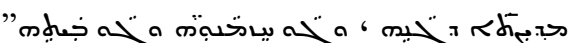

Arabic Version:

$$
\text { ولكِنَ يَسُوع قالَ لَهُم (لا يكونُ النبيُّ بلا كر امة إلا في بلدنه، وبينَ أقربائهِ }
$$

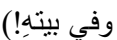

Analysis

A close look at the three versions of the Holy Bible, verse namely (1) English, (2) Syriac and Arabic reveals that there are somehow differences and similarities among them. These similarities and differences are in semantic structure, translation and intentionality, which emerges from pragmatic analysis. Concerning the analysis of the semantic structure, it is apparent that the semantic structure of the verse in English version is deviated from the norm, simply, because the predicate has been foregrounded and has become the grammatical subject of the whole verse. In regard to Syriac and Arabic, it seems that this deviation has not been taken into consideration. A comparative analysis of the three versions, one may say that both Syriac and Arabic are the output of the semantic translation if and only if they have been taken from English. Regarding, the translation of the English version, as compared with the Syriac and Arabic versions, it seems 
to be the output of communicative translation coloured by adaptation in order to show the pragmatic effect of markedness theory. As for the intentionality of the translators, it is clear that English version confirms the idea that the prophet has honesty, but his relatives and those who know him in his hometown do not believe in that .Hence comes the foregrounding of the word "only" which presupposes that the prophet has "honesty" but not in his hometown and with his relatives. Consequently, this foregrounding is to make "honor" marked ,simply, because it is sacred. This leads us to say that the English version may approach the original Greek or Hebrew versions, if and only if the original version of the Bible is Greek or Hebrew.

A. English Version(2):Soon afterward, Jesus went to a town called Nain, and his disciples and a large crowd went along with him. (Luke 7:11, P.191)

B. B. English Marked Version: Soon afterward, Jesus went to a town called Nain, and his disciples and a large crowd went along with him.

\section{C. English Norm Version:}

Jesus went to a town called Nain soon afterward, and his disciples and a large crowd went along with him.

\section{Syriac Version:}

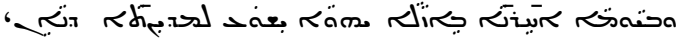

$$
\begin{aligned}
& \text { ملأ }
\end{aligned}
$$

Arabic Version:

$$
\text { وفيمُ اليوح التالي، ذهبَ إلى مدينةٍ اسمُهَا نايينُ، بر اققه كثيرون من نلاميذه }
$$

\section{Analysis}

A close inspection of the three versions, one can recognize that these versions are in three different languages, namely, (1) English (2) Syriac and (3) Arabic. As for English, it is clear that the adverb of time "soon afterward " has been foregrounded by putting it at the beginning of the angelic verse. This foregrounding may be due to two reasons or possibilities: (1) the semantic meaning of this verse is a continuation of the previous verse as a discourse which can be called grammatically conjunction or transitional linker, and (2) the semantic meaning of this verse reveals that this verse and both the previous and the following ones are a sort of narrating the story of Jesus. As a result, markedness is used. In regard to both (1) and (2), it seems, that the same procedure has been used with both Syriac and Arabic .Regarding translation, it seems that the semantic translation has been used and coloured by communicative translation because of some changes of lexicons and a little bit slight changes in the syntactic structure, Considering, pragmatic analysis of the verse, it is apparent that the elements that have been marked come as a response to the importance of the main incidences to give the intended meaning more force to the transitional linkers that will match the narration style.

A. English Version (3) :Now, brothers, I want to remind you of the gospels I preached to you, which you received and on which you have taken your stand. (1Corinthians 15:1 p. 521).

B. English Marked Version: Now, brothers, I want to remind you of the gospels I preached to you, which you received and on which you have taken your stand.

C. English Norm Version: I want to remind you, brothers, now of the gospels I preached to you, which you received and on which you have taken your stand.

Syriac Version:

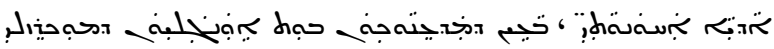

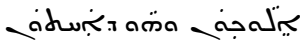

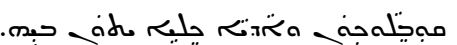

\section{Arabic Version:}

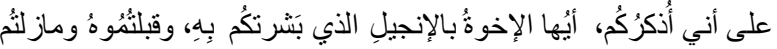

$$
\begin{aligned}
& \text { قائمينَ فيهـ. }
\end{aligned}
$$

Analysis

A comparative analysis of the three versions in question ,namely (1) English, (2) Syriac and (3) Arabic, one can say that the marked elements are rather clear "الان أيها الأخوه اريد "now brothers “ in English " "in Syriac, in Arabic علي ان اذكركم أيها الإخوة Hence, differences occur, simply, because in Arabic the adverb الان has not been used, whereas in both English and Syriac has been confirmed. Another point should be added that both English and Syriac used request as a Speech Act whereas Arabic has used an obligation form which is a sort of demand .Regarding translation, it seems that both English and Syriac undergo semantic translation, whereas Arabic undergoes communicative translation since there are deletion or addition .As for the pragmatic notion "intentionality" " it is very obvious that in general the adverbs of time have been regarded as the marked elements, simply, because these elements represent time markers which can be considered as one of the most important elements or features of the style of narration .

A. English Version (4): "24 But in those days, following that distress, the sun will be darkened, and the moon will not give its light; ${ }^{25}$ the stars will fall from the sky, and the heavenly bodies will be shaken". (Mark 13:24,25 p. 149)

B. English Marked Version: But in those days, following that distress, the sun will be darkened and the moon will not give its light; the stars will fall from the sky, and the heavenly bodies will be shaken".

C. English Norm Version: The sun will be darkened and the moon will not give its light; the stars will fall from the 
sky, and heavenly bodies will be shaken but in those days, following that distress.

Syriac Version:

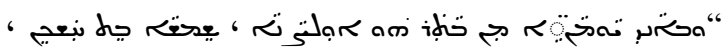

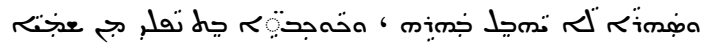

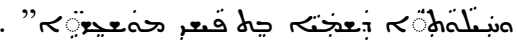

\section{Arabic Version:}

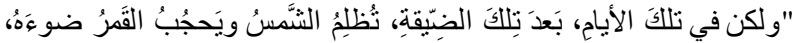

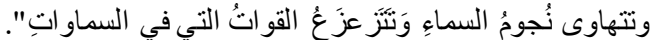

\section{Analysis}

Regarding these texts, one can see that there are three versions (1) English, (2) Syriac and (3) Arabic. It seems that there is no marked elements. Whatever is mentioned follows the norm, i.e. in an accordance with the grammatical rules and structures of the English Language.

Even the phrase "but in those days, following that distress" though it shows sequence implicitly, it has not been marked, simply, because it shows contrast rather than sequence because of the conjunction "but".

As for as the whole verse are concerned, it seems that the three versions have sequence of sentences with complete grammatical structures matching the grammatical rules of the language in question. Only, in the Syriac version markednesshas been confirmed in that subjects were foregrounded and verbs were backgrounded. With regard to translation, we are unable to decide which type of translation has been used exactly for text, simply, because we are not in an excess of the original copy. However, as a comparative study., it is clear that semantic translation has been used in both English and Arabic. As for Syriac, it is rather clear that communicative translation is used since all the sequences of sentences of the holy verse have been marked.

A. English Version (5):Fourteen years later I went up again to Jerusalem, this time with Barnabas. I took Titus along also. (Galatians 2:1, p.558)

B. English Marked Version: Fourteen years later I went up again to Jerusalem, this time with Barnabas. I took Titus along also.

C. English Norm Version: I went up again to Jerusalem fourteen years later, this time with Barnabas. I took Titus along also.

\section{Syriac Version:}

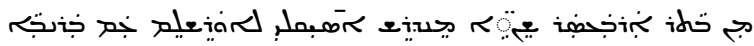

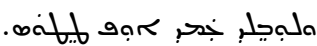

Arabic Version:

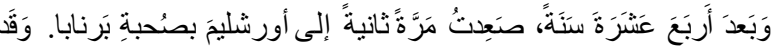

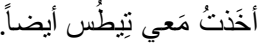

Analysis
A close look at this verse, with three different versions namely (1) English, (2) Syriac, and (3) Arabic, one can say that the emphasis has been put on the adverbial phrase of time, since it has been foregrounded, which means it has been marked to show that the most salient element of the verse is time. As for Syriac, it seems that the same procedure has been done in that the adverbial phrase of time has been marked by foregrounding since the focus is on time. In regard to Arabic language, it is clear that the same element has been foregrounded and thus marked. One extra element has been added in Arabic which is the conjunction " 9 (meaning "and") to show that the incident in the verse is the sequence of the previous verse. Because there is markedness element, it is believed that communicative translation has been used. This comes in accordance with the intentionality of three translators if and only if the original source was marked.

A. English Version (6):" Blessed are the poor in spirit, for theirs is the kingdom of heaven". (Matthew 5:3, p. 9). B. English Marked Version:" Blessed are the poor in spirit, for theirs is the kingdom of heaven.

C. English Norm Version: The poor in spirit are blessed , the kingdom of heaven is for theirs.

\section{Syriac Version:}

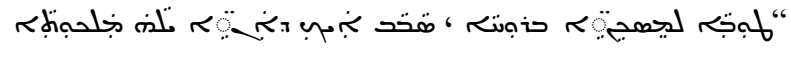

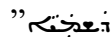

Arabic Version:

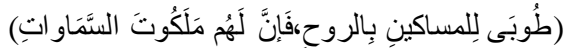
Analysis

The three versions of the angelic verse are (1) English, (2) Syriac, and (3) Arabic. It seems that all versions are used in a sort of structure which is suitable for saying prayers and requesting the Almighty God to let them know that they will win his satisfaction and mercy; and His heavenly world. Concerning the markedness elements, it seems that the English version confirmed the lexicon "Blessed" as a requesting prayer, whereas Syriac used " لمجّ" ".

In regard to Arabic, it is obvious that the word "طوبى"has been used as a requesting prayer. This means that markedness elements have been achieved through the use of lexicons. As it is well-known prayers, in English are used through the subjunctive structures just like " May God bless the spirits of these poor people" or just “ God bless the spirit of these people".

As for Arabic, it seems that lexicon "طوبى"has been used as a marker of markedness.

Usually, in Arabic, "اللهم بارك"is used. So all the versions have been deviated from the norm for saying the prayer. 
Considering, translation, we can say that both semantic and communicative methods have been used. Semantic, in the sense of the versions in their current status, whereas communicative, in the sense of deviation from the norm and choosing another structure for saying prayers.

A. English Version (7): Jesus looked at them and said "With man this is impossible, but with God all things are possible." (Matthew 19:26, p. 62)

B. English Marked Version: With man is impossible, but with God all things are possible.

C. English Norm Version: This is impossible with man, but all things are possible with God.

Syriac Version:

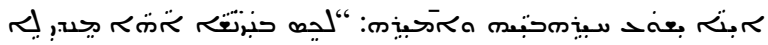

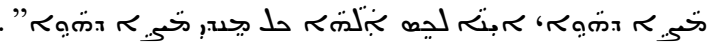

Arabic Version:

$$
\text { فنظر إليهم وَقَالَ لَهُج(هذا مستحيلٌ عِندَ الناس. أما عِندَ اللهِ، فكلُ شيءٍ }
$$

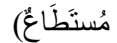

Analysis

Having a glance at the three versions of the verse, it reveals that in English there is marked element which is "with man" since it has been forgrounded. As a matter of fact the norm should have been "This is impossible with man". Regarding Syriac version, it is apparent that the phrase"لحه حنرتى "has been forwarded for confirmation, thus becomes marked. In regard to Arabic version, it is clear that the markedness has not been taken into consideration. The norm structure has been used without any deviation.

With reference to the pragmatic analysis and mental state of intentionality, it is crystal clear that the marked elements "with man" and "عند الناس"have been confirmed strongly since it is impossible that human beings can do everything or what God is able to do. Human being is helpless in achieving things but God is helpful and powerful to do everything. Nothing is impossible for HIM, but most of things for human being is impossible since his capacity and ability are limited. Hence, the markedness comes. Regarding translation, it seems that in both English and Syriac communicative translation has been used, simply, because of the use of marked element. However, with Arabic version it appears that semantic translation is used because norm of the structure has been confirmed.

A. English Version(8): "No good tree bears bad fruit, nor does a bad tree bear good fruit. (Luke 6:43, p189)

B. English Marked Version: No good tree bears bad fruit, nor does a bad tree bear good fruit.

C. English Norm Version: Good tree does not bear bad fruit and bad tree does not bear good fruit.

Syriac Version:

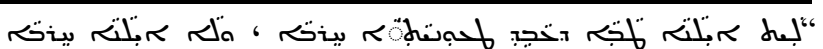

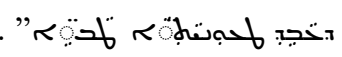

Arabic Version:

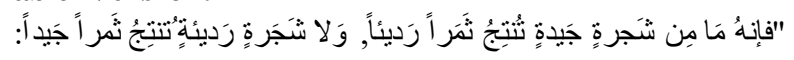
Analysis

A comparative analysis of the three translated versions of the angelic verse reveals that markedness has been taken into consideration. The marked element is in the scope of negation. In English version, the marked element is in the scope of negative article, "No". The "Norm" version could have been as in this structure "Good tree does not bear bad fruit". However, it has been foregrounded to confirm the meaning of the verse which lies in "No good tree". In regard to Arabic version, it seems that the negation article "ما" has changed the scope of the verse to show that" good tree does not bear bad fruit". Concerning the Syriac version, it is clear that the negative particle has been forwarded to the beginning which changes the scope of negation and thus to put emphasis on the negative element which is مامن شجرة " مئة " جيدة" since the basic meaning is "شجرة جيدة"

As for translation, it seems that communicative method of translation has been used, simply, because marked element has been confirmed to match the meaning of the verse if and only if we know the source language of the verse.

A. English Version(9): Trembling and bewildered, the women went out and fled from the tomb. They said nothing to anyone, because they were afraid.(Mark: 16:8, P. 161)

B. English Marked Version: Trembling and bewildered, the women went out and fled from the tomb. They said nothing to anyone, because they were afraid.

C. English Norm Version: The women went out and fled from the tomb trembling and bewildered. They said nothing to anyone, because they were afraid.

Syriac Version:

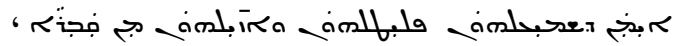

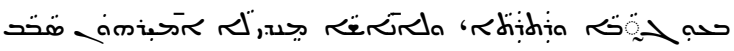

$$
\begin{aligned}
& \text { טتخمعهחם. }
\end{aligned}
$$

Arabic Version:

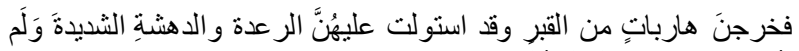

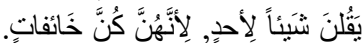

\section{Analysis}

Having a look at these three versions of the verse under discussion and analysis, one can see that the phrase "trembling and bewildered" has been foregrounded on the basis of describing the status of the women once they were out, simply, because the meaning lies there. Regarding Syriac version, it seems that the marked "element is 
has been forwarded to confirm the phrase at the time of hearing "they were trembling and shivering" بتعجب" ور عدة" With reference to the Arabic version, it is apparent that the status of women, while they were going out has been confirmed through the use of the expression فخرجن "هاربات, because " هاربات, implicitly describes the status of the women, while they were running and going out. Regarding intentionality, we can say that the most important thing in this verse is the status of women being terrified and afraid from seeing that.

Consequently, markedness takes place to confirm "trembling and bewildering, "هاربات" , and running away. As for translation, it is clear that different types were used such as semantic translation and communicative translation, but we cannot decide which one, simply, we are not in access of the source language.

A. English Version(10):On hearing it, many of his of disciples said," This is a hard teaching. Who can accept?" (John 6:60, p. 291)

B. English Marked Version: On hearing it, many of his of disciples said," This is a hard teaching. Who can accept?"

C. English Norm Version: Many of his of disciples on hearing it said, this is a hard teaching. Who can accept it? Syriac Version:

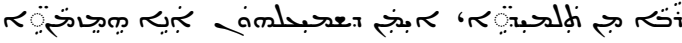

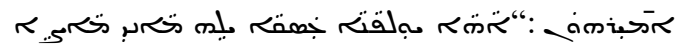

$$
\begin{aligned}
& \text { " }
\end{aligned}
$$

Arabic Version:

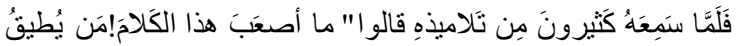

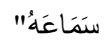

Analysis

A comparative analysis of the three versions of the verse in question, one can see that in the English version, the phrase" On hearing it" has been marked by foregrounding and putting it before the grammatical subject "many of his disciples" and thus became part of the grammatical subject, since time here is very significant, simply, because the consequences have a great impact on them at the moment of announcing that. As for Arabic, it seems that the phrase"فلما سمعه كثيرون" also has been marked by foregrounding to confirm that the disciples became surprised at the moment of hearing that. In regard to Syriac version, it is clear that the expression "كثيرون من تلاميذه" has been marked by foregrounding. Pragmatically speaking, this phrase تكنيرن "كنيرون "قليل من تلاميذه" were not surprised and just remained without being angry or nervous. Regarding translation, the same problem occurs which is not in full access of the original text to decide. However, because there are some differences among the three versions. One can say that the communicative translation was used, simply, because there are certain changes.

\section{CONCLUSIONS}

The main conclusions the study arrived at are as follows:

1. The three versions: English, Syriac and Arabic were the output of communicative translations in, that structurally speaking, differences among the three versions are recognizable.

2. Confirmation of certain key-words which convey the gist of the verse has been marked and considered by the translators mainly by foregrounding and sometimes by midgrounding and backgrounding through shifts from grammatical rules.

3. Concerning the literature review of the research, translation has been viewed in terms of the transference of meaning and finding equivalence. Our notion of translation will be in terms intentionality in the sense that all linguistic elements in our study and non-linguistic elements in other studies, which concern language in interaction, should be taken into account.

4. Linguistically, markedness means the way words, phrases are changed, added, deleted or foregrounded, midgrounded and backgrounded, this is our case. However, markednesscan be used through other devices like superasegmental features (e.g. stress, intonation, rhythm, pause, and juncture.

5. Markednesshas been defined phonologically, morphologically, syntactically, semantically and pragmatically. Our notion of markedness is that whenever there is any prominence, or salience, it will be considered as marked. However, the study in question will consider any shift or violation from the grammatical rules as marked.

\section{REFERENCES}

[1] Al-Sulaimaan, M. M. (2016): Translation: Theory and Practice, Erbil: Haval Art Printing Press.

[2] Al-Sulaimaan, M. M. \& R.S. H. Al-Juboury, (2018): "Collocational Partitive Constructions." In: M.M. Al-Sulaimaan (ed.)Translation Semantically and Pragmatically Oriented, Erbil: Haval Art Printing Press, pp. 45-95.

[3] Auer, P. (2009): "Context and Contextualization". In: JefVerschneren (ed.), Key Notions for Pragmatics, pp. 86-101.

[4] Berrendonner, Alain (1990): "Pour Une Marco Syntaxe" Travux-de Linguistique, 21: pp. 2526. 
[5]

Pragma-Syntaxe,

(2000): "Morpho-Syntaxe,

Semantiques",Linguistique ,22, pp.23-41.

[6] Catford, J.C. (1965): A Linguistic Theory of Translation, London: Oxford University Press.

[7] Cornish, Francis (2014): "Micro-Syntax, Macrosyntax,Foregrounding and Backgrounding in Discourse", Belgian Journal of Linguistics, 26, pp. 6-34.

[8] Greenberg, J.H. (1966): Language Universal, with Special Reference to Feature Hierarchies, The Hague: Mouton.

[9] Harely, H. Ritter, E.(2002a): "Person \& Number in Pronouns: A Feature-Geometric Analysis". Language 78/3: pp. 482-526.

[10] (2002b): "Structuring the Bundle: A Universal Morphosyntactic Features Geometry". In: Horst. J.

[11] Simon and Heik Wiese (eds.) Pronouns: Grammar and Representation, Amsterdam: John Benjamins, pp. 110-112.

[12] Hunang, Yan. (2000): Anaphora: A CrossLinguistic Study, Oxford: Oxford University Press.

[13] Khalil, Esam-N. (2005): "Grounding: Between Figure-Ground and Backgrouning", Annual Review of Cognitive Linguistics, 20,3: pp.1-21.

[14] Kieswetter, A. (1995): Code-Switching Among African High School Pupils. Witwaters rand Occasional Papers inLinguistique 1.

[15] Leech, G. N. (1969): A Linguistic Guide to English Poetry, London: Longman.

[16] Myers-Scotton, C. (1993): Language: Grammatical Structure in Code Switching, Oxford: Oxford Clarendon Press.

[17] Newmark, P. (1982): A Textbook of Translation, London: Prentice Hall.

[18]____________ (1988): Approaches to Translation, Oxford: Pergamon.

[19] Nida, E. (1975): Exploring Semantic Structure, Munich: Fink.

[20] Nida, E., and C.R. Taber (1982): The Theory and Practice of Translation, Leiden:E.J. Brill.

[21] Nida, E. (1994): "Translation: Possible and Impossible".Turjuman,Vol.3, No.2, pp. 147163.

[22] (1995): "Dynamic Equivalence in Translating", In: Chan, Sin-Wai and D.E. Polland (eds.), Translation Studies,pp. 223-230.

[23] Nord, Richard(2017): $\quad$ Foregrounding: Definitions and Examples, www. Thoughts.com.
[24] Noyer, R. (1992): Features Positions and Affixes in Autonomous Dissertation, (Unpublished Dissertation), Massachusetts University.

[25] Trubetzkoy, N. S. \& R. Jakobson(1939): Oxford Research Encyclopedia Linguistics, Oxford: Oxford University Press.

[26] (1969): Principles of Phonology, Berkely: California University Press.

[27] Yan-qin, Z. \& Feng-Jvan, T. (2015): "Study on Markedness in Linguistics". Sino-us English Teaching, Vol. 12, No. 9, pp. 66-671. 